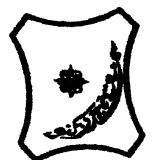

Bayero Journal of Pure and Applied Sciences, 9(1): 48 - 52

Received: November, 2015

Accepted: April, 2016

ISSN $2006-6996$

\title{
EFFECT OF AQUEOUS SEED EXTRACT OF Nigella sativa ON LEAD-INDUCED CEREBRAL CORTEX TOXICITY IN LONG EVANS RATS
}

\author{
Bauchi, Z.M.,* Kizito, D.,* Alhassan, A.W., ** Akpulu, S.P.* and Timbuak, J.A.* \\ *Department of Human Anatomy, Faculty of Medicine, Ahmadu Bello University, Zaria, Nigeria \\ ** Department of Human Physiology, Faculty of Medicine, Ahmadu Bello University, Zaria, Nigeria
}

\begin{abstract}
Lead $(\mathrm{Pb})$ is a widespread toxic metal found in the environment with potential danger to human health. It is used in the manufacture of batteries, metal products, paints and other domestic substances. This study investigated the effect of aqueous seed extract of Nigella sativa on leadinduced cerebral cortex toxicity in Long Evan's rats. Twenty five Long Evans rats divided into five groups of five animals were used for the study. Group I received Distilled water, group II received aqueous seed extract of Nigella sativa (1000 $\mathrm{mg} / \mathrm{kg})$, group III received lead $(60 \mathrm{mg} / \mathrm{kg})$, group IV received lead $(60 \mathrm{mg} / \mathrm{kg})$ followed by aqueous seed extract of Nigella sativa (1000 $\mathrm{mg} / \mathrm{kg})$ and group $V$ received lead $(60 \mathrm{mg} / \mathrm{kg})$ followed by aqueous seed extract of Nigella sativa $(500 \mathrm{mg} / \mathrm{kg})$ via oral intubation. Elevated Plus Maze (EPM) was used to study anxiety-like behaviour. Activities on the elevated plus maze showed that there was no statistically significant decreased rate of anxiety across the groups (P>0.05). The histology of the cerebral cortex of long Evans rats in group IV that received Lead $(60 \mathrm{mg} / \mathrm{kg})$ followed by aqueous seed extract of Nigella sativa $(1000 \mathrm{mg} / \mathrm{kg})$ showed mild neuronal damage while the histology of group $V$ animals that received lead $(60 \mathrm{mg} / \mathrm{kg})$ followed by aqueous seed extract of Nigella sativa $(500 \mathrm{mg} / \mathrm{kg})$ showed severe neuronal damage. It can be concluded that aqueous seed extract of Nigella sativa at high dose have more therapeutic effect than at low dose.
\end{abstract}

Keywords: lead, Nigella sativa, elevated plus maze, cerebrum

\section{INTRODUCTION}

Heavy metals are essential as trace elements or trace metals to all living organisms, but severe concentrations can cause severe toxic effects on organisms such as humans, plants and animals. (Poli et al., 2009). Lead is a highly toxic substance, exposure to which can produce a wide range of adverse health effects. Lead is a poison that affects virtually every system in the human body. It is particularly harmful to the developing brain and nervous system of fetuses and young children. It is highly toxic and can interrupt the body's neurological, biological and cognitive function. Understanding the mechanism of lead toxicity has advanced substantially over the past decades, and focus has shifted from high-dose effects in clinically symptomatic individuals to the consequences of exposure at lower doses that cause no symptoms, particularly in children and fetuses (Fewtrell et al., 2003) Lead poisoning is one of the oldest and the most widely studied occupational and environmental hazards. It remains one of the most common and preventable pediatric environmental conditions in the United States. Medical workers in Nigeria reported that the lead concentration in Zamfara State ore is so toxic that in 2010 in seven villages the mortality rate was estimated as high as 40 percent among children who showed symptoms of lead poisoning (Elombah and HRW, 2012).
Lead is a toxic metal whose widespread use has caused extensive environmental contamination and health problems in many parts of the world. It is a cumulative toxicant that affects multiple body systems, including the neurological, haematological, gastrointestinal, cardiovascular and renal systems. Children are particularly vulnerable to the neurotoxic effects of lead, and even relatively low levels of exposure can cause serious and, in some cases, irreversible neurological damage (Fewtrell et al., 2003). According to the World Health Organization, high levels of lead exposure can cause brain, liver, nerve, and stomach damage, as well as permanent intellectual and developmental disabilities (Elombah and HRW, 2012). Lead exposure is estimated to account for $0.6 \%$ of the global burden of disease, with the highest burden in developing regions (WHO 2009). Compared to other organ systems, the nervous system appears to be the most sensitive and chief target for lead induced toxicity (Cory-Slechta, 1996). The cerebral cortex seems to be the most affected areas in the brain (El-Neweshy and El-Sayed, 2011). With the increase in human life expectancy, the incidence of age-related neurodegenerative disorders such as Alzheimer's disease, Parkinson's disease, and Huntington's disease has also increased (Borgesius et al., 2011). Plant extracts have a wide range of medicinal actions, and throughout history, they have been used to treat many different types of diseases. 
The biological activities of medicinal plants including their neuroprotective actions has become a popular area of investigation for scientists.

Nigella sativa ( $N$. sativa) (Family Ranunculaceae) has emerged as a miracle herb with a rich historical and religious background. Numerous researchers have revealed its wide spectrum of pharmacological potential. $N$. sativa is commonly known as black seed. The plant is native to Southern Europe, North Africa and Southwest Asia and it is cultivated in many countries in the world like Middle Eastern Mediterranean region, South Europe, India, Pakistan, Syria, Turkey, Saudi Arabia (Khare, 2004).

The seeds of $N$. sativa and their oil have been widely used for centuries in the treatment of various ailments throughout the world. And it is an important drug in the Indian traditional system of medicine like Unani and Ayurveda (Sharma et a/2005). Among Muslims, it is considered as one of the greatest forms of healing medicine available. This study aimed at investigating the effect of aqueous extract of $N$. sativa seeds on lead induced neurotoxity in the cerebrum.

\section{MATERIALS AND METHODS}

Twenty five (25) adult Long Evans Rats were used for this study. The animals were allowed to acclimatize for two weeks prior to the experiment. The animals were grouped into five groups of 5 animals each. Group I received Distilled water and served as control, group II received aqueous seed extract of Nigella sativa $(1000 \mathrm{mg} / \mathrm{kg})$, group III received lead $(60 \mathrm{mg} / \mathrm{kg})$, group IV received lead $(60 \mathrm{mg} / \mathrm{kg})$ followed by aqueous seed extract of Nigella sativa $(1000 \mathrm{mg} / \mathrm{kg})$ and group $\mathrm{V}$ received lead $(60 \mathrm{mg} / \mathrm{kg})$ followed by aqueous seed extract of Nigella sativa $(500 \mathrm{mg} / \mathrm{kg})$. Lead toxicity was achieved by administration of lead acetate $(1000 \mathrm{mg} / \mathrm{kg})$ for 3 weeks. Aqueous extract of $N$. sativa was administered for 2 weeks. Administration was through oral intubation. After the period of administration, the animals were subjected to neurobehavioural tests using the elevated plus maze.

\section{Neurobehavioral testing}

The rats were placed in the central square of the Elevated Plus-Maze (Walf and Frye, 2007) facing an open arm and then allowed to explore the apparatus for 3 minutes. The maze was then cleaned with a solution of $70 \%$ ethyl alcohol and allowed to dry between tests. Behaviors scored were:

I. Rearing: Frequency with which the animal stands on its hind legs or leans against wall of the maze with front paws.
II. Closed Arm Entries: Frequency with which the animal entered the closed arms. All four of the rat's paws should be in the closed arms to be regarded as an entry.

III. Closed Arm Duration: Length of time the animal spent in the closed arms.

IV. Grooming: Frequency with which animals brushed its body.

The premise behind the elevated plus maze was that more anxious rats will spend less time in the uncovered, exposed arms of the maze and less anxious rats will explore the open arms more freely (Shepherd, et al.,1994).

After neurobehavioural testing, the animals were sacrificed using chloroform inhalation and the brains removed and fixed in $10 \%$ formal saline. The tissues were then histologically processed and stained with Hematoxylin and Eosin.

\section{Data Analysis}

Statistical Package for the Social Sciences (SPSS) Version 21 was used to perform one-way analysis of variance (ANOVA), Results were expressed as standard error of mean (SEM), with $p<0.05$ considered statistically significant.

\section{RESULTS}

Effect of aqueous seed extract of $\boldsymbol{N}$. Sativa on anxiety in lead induced toxicity

The activities of the Long Evans rats in the closed arms of the Elevated Plus Maze revealed that there was no statistical decrease in time spent on the closed arms across the groups $(P<0.05)$. Group I had mean time of $167 \pm 12.76$ seconds, while group II, III, IV and $V$ had mean values of $155 \pm 22.19$ seconds, 144 \pm 22.15 seconds, $141 \pm 37.67$ seconds, and $156 \pm$ 22.03 seconds respectively. The animals in group IV spent least time in the closed arm of the maze, signifying a decrease in anxiety; the time however was not statistically significant.

There was also no significant decrease in the number of closed arm entries of the elevated plus maze ( 0.69 , $0.08,0.21$ and 0.69). Rats in group I had mean entries of $4.66 \pm 1.52$ times to the closed arms while group II, III, IV and V had $1.33 \pm 0.57$ times, $3.80 \pm$ 0.44 times, $4.00 \pm 1.15$ times, $4.00 \pm 2.64$ times respectively. The animals did not display significant changes in grooming. Rats in group I had mean grooming of $3.66 \pm 0.57$ times, while rats in group II, III, IV and V had mean grooming of $3.00 \pm 0.00$ times, $2.50 \pm 1.00$ times, $2.00 \pm 1.00$ times, $4.00 \pm$ 1.73 times respectively.

Table 1: Results of Neurobehavioural testing in Rats After Administration of Aqueous seed Extract of Nigella Sativa

\begin{tabular}{lcccccc}
\hline & GROUP1 & GROUP2 & GROUP3 & GROUP4 & GROUP5 & \\
\hline & Mean \pm SEM & Mean \pm SEM & Mean \pm SEM & Mean \pm SEM & Mean \pm SEM & $P$-value \\
CAD & $16.70 \pm 12.76$ & $15.50 \pm 22.19$ & $14.40 \pm 22.15$ & $14.10 \pm 37.67$ & $15.60 \pm 22.03$ & 0.69 \\
CAF & $4.66 \pm 1.52$ & $1.33 \pm 0.57$ & $3.80 \pm 0.44$ & $4.00 \pm 1.15$ & $4.00 \pm 2.64$ & 0.08 \\
GRM & $3.66 \pm 0.57$ & $3.00 \pm 0.00$ & $2.50 \pm 1.00$ & $2.00 \pm 1.00$ & $4.00 \pm 1.73$ & 0.21 \\
RRG & $6.33 \pm 3.78$ & $3.33 \pm 1.15$ & $4.60 \pm 2.07$ & $5.75 \pm 4.19$ & $6.50 \pm 2.12$ & 0.69 \\
\hline
\end{tabular}

MEAN \pm SEM of Closed Arm Duration (CAD), Closed Arm Frequency (CAF), Grooming (GRM) and Rearing (RRG). No significant difference was observed 


\section{Histological Evaluation}

Analysis of the histology of the cerebral cortex of the animals treated with aqueous extract of seeds of $N$. sativa (plate 2) showed normal cells and some pyknotic cells. The histology of the cerebral cortex of the lead only treated group (plate 3 ) showed severe vacoulation and areas of necrosis. Plate 4 shows a section of the cerebral cortex of animals in group IV (lead acetate $+1000 \mathrm{mg} / \mathrm{kg}$ of extract) displaying

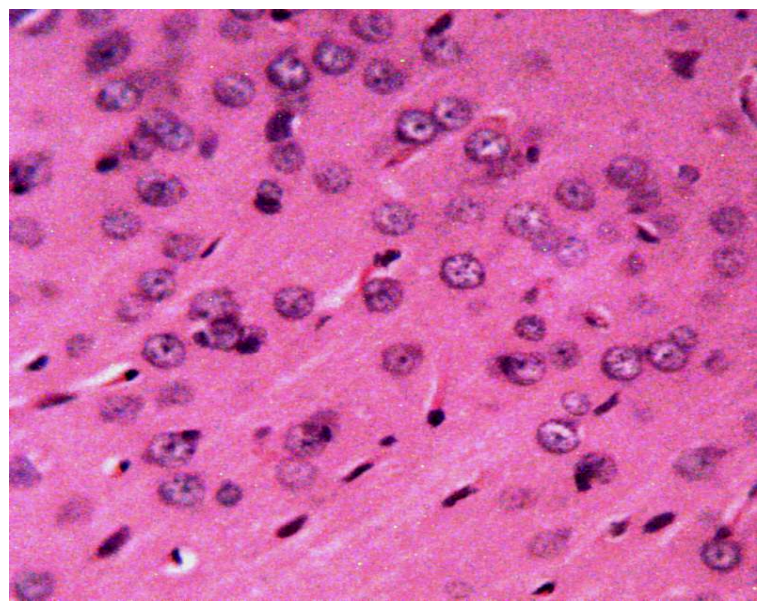

Plate 1: transverse section of the cerebral cortex of the control group showing normal cytoarchitecture (H \& E x250)

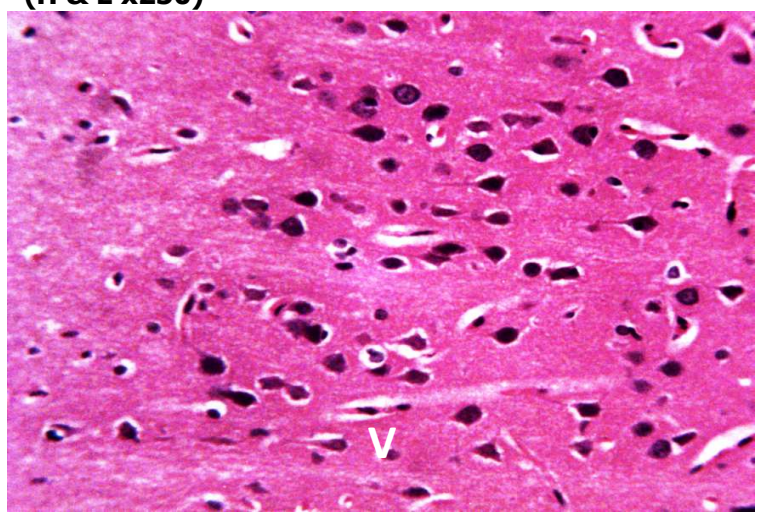

Plate 3: transverse section of the cerebral cortex of the group III showing vacoulation (V) and pyknotic cells(PC) (H \& E x250)

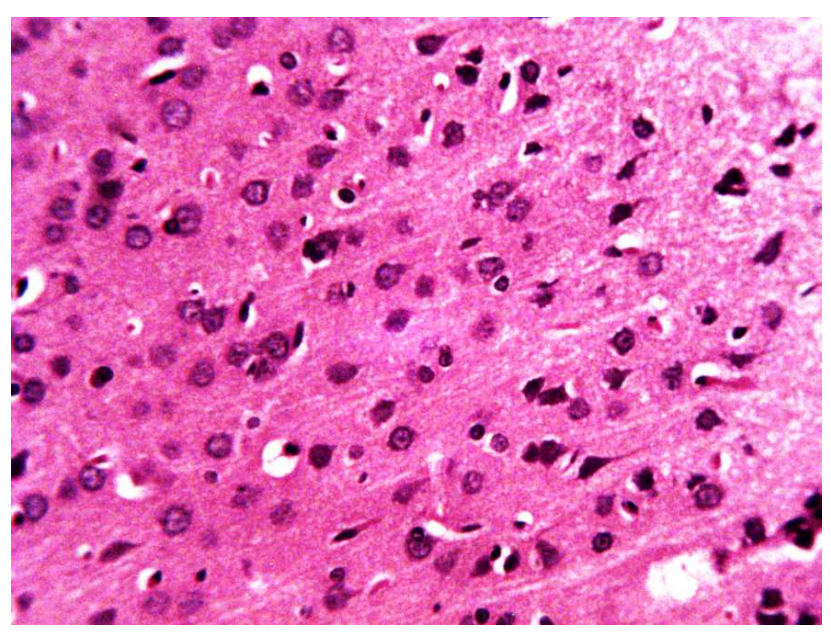

Plate 5: transverse section of the cerebral cortex of the group $V$ showing vacoulation (V), pyknotic cells (PC) and numerous necrotic cells(NC) (H \& E x250) viable cells with some necrotic cells visible. The histology of the animals in group $\mathrm{V}$ (lead acetate + $500 \mathrm{mg} / \mathrm{kg}$ extract) also showed a few viable cells, however cells showing signs of necrosis were evident. The histology of the animals in groups IV and V displayed better architecture than the lead acetate group. The higher dose of the extract (group IV) appears to have had a greater effect on the lead induced damage than the lower dose.

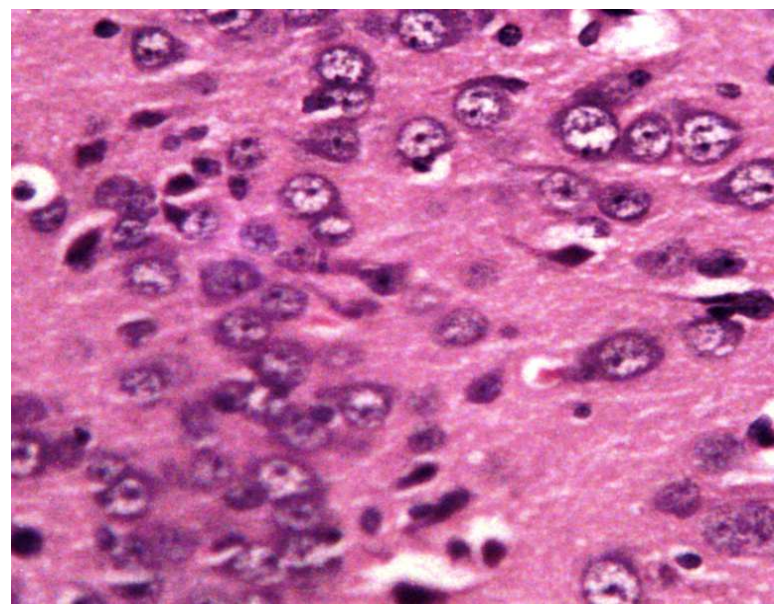

Plate 2: transverse section of the cerebral cortex of the group II showing normal cells (NC) and a few pyknotic cells (PC) (H \& E x250) (H \& E x250)

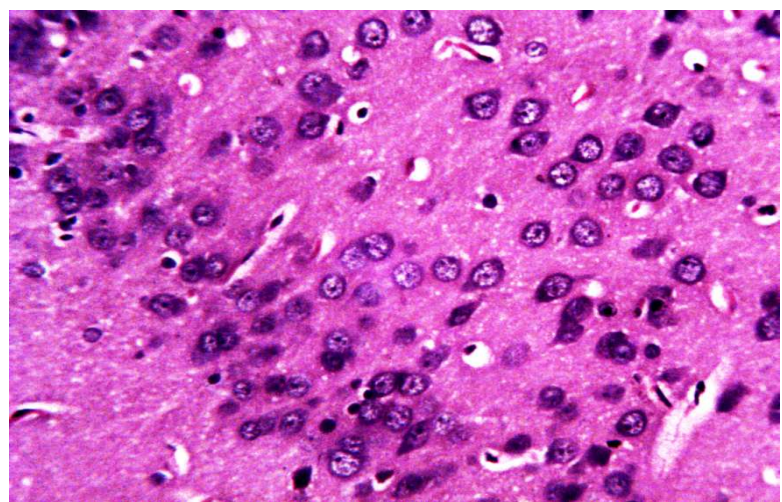

Plate 4: transverse section of the cerebral cortex of the group IV showing vacoulation (V), a few necrotic cells (NC) and viable cells (VC) (H \& E 


\section{DISCUSSION}

The validity of the EPM test for evaluation of anxiolytic or anxiogenic effects of drugs has been well documented (Carobrez and Bertoglio, 2005). Exposure to the Elevated Plus Maze test induces behavioural and physiological effects in rodents consistent with fear and anxiety. The animal is placed in the centre of an elevated four-arm maze where only two of the arms are enclosed and the increase in time spent in the closed arms reflects increased anxiety.

Several plants that are used in folk medicine to diminish anxiety are reported to bring about decrease in the exploration of the closed arms in the EPM test (Thakur, et al., 2005). In EPM, naïve rat will normally prefer to spend much of their allotted time in the closed arms. Drugs that decrease closed arm exploration are considered as anxiolytic and the reverse holds true for anxiogenic (Hellion-Ibarrola, et al., 2006). In the present study we observed that the aqueous seed extract of Nigella sativa decreased both the number of entries and time spent in the closed arms of the Elevated Plus Maze. The results however showed no statistical significance at $p<0.05$ (table 1 ). The rearing and grooming behavior of the animals was also decreased, but not to any statistically significant extent. These results are similar to the findings of other researchers who examined neurobehavioural function after administration of $N$. sativa. Al-Naggar et al (2003) evaluated the central analgesic effects of methanol and aqueous extract of $N$. sativa using hot-plate test and pressure test and that reaction time in the hot-plate test and pressure tests are significantly increased by both extracts and Azzubaidi et al (2012) who demonstrated that $N$. sativa seeds could significantly preserve the spatial cognitive function in rats challenged with chronic cerebral hypoperfusion. Other researchers have reported that $N$. sativa can prevent the damage of spatial memory after scopolamine administration and reduced the acetylcholinesterase (AChE) activity as well as oxidative stress of the brain tissue in rats (Hosseini et al, 2015). Researches using animal models have shown that lead toxicity could be associated with oxidative stress via the generation of reactive oxygen species and can be mitigated by some antioxidants, materials of animal origin and extracts of plant origin (Adikwu et al., 2013). The present findings agree to the fact that natural compounds that are rich in antioxidants help to reduce oxidative stress thus alleviating the effect of oxidative agents (Ahamed and Siddiqui, 2007).

The present study showed pyknosis of cerebral cortical cells and necrosis of cells in adult Long Evan's rats administered with lead acetate $60 \mathrm{mg} / \mathrm{kg}$ (group III), while the layers and cells of cerebral cortex of the Control Group showed normal histology (plate 1). Researchers such as Xu et al (2009) have reported lead impairment in brain architecture and function on exposure to lead. The present study has revealed some therapeutic effect of Nigella sativa on the cerebral cortex in the experimental animals induced with lead acetate toxicity. The histology of the cerebral cortex of long Evans rats in group IV that received Lead II acetate $(60 \mathrm{mg} / \mathrm{kg})$ for three weeks followed by aqueous seed extract of N. sativa (1000 $\mathrm{mg} / \mathrm{kg}$ ) for two weeks (group IV) showed many viable cells with few necrotic cells (plate 4). While the histology of the long Evans rats in group $\mathrm{V}$ that received Lead II acetate $(60 \mathrm{mg} / \mathrm{kg})$ for three weeks followed by aqueous seed extract of Nigella sativa $(500 \mathrm{mg} / \mathrm{kg})$ for two weeks, showed many necrotic cells with few viable cells (plate 5). Administration of Nigella sativa has shown some improvement in the cerebral cortex when compared with rats exposed to lead acetate only. The present finding shows that Nigella sativa has reduced the damage done to the cerebral cortex and this agrees to the fact that natural compounds that are rich in antioxidants help to reduce oxidative stress thus alleviating the effect of oxidative agents (Ahamed and Siddiqui, 2007). Kanter (2008) obtained similar results when he evaluated the effects of $N$. sativa on induced neuronal injury by chronic toluene exposure in the frontal cortex and brain stem in rats. He reported no histopathological lesions after treatment with $N$. Sativa for 12 weeks. $N$. Sativa also provided protection to hippocampal cells exposed to lead and the frontal cortex (Kanter, 2011). The findings of this study also indicate a dose dependant relationship.

\section{CONCLUSION}

In light of the observed changes in cytoarchitecture, it can be concluded that aqueous extract of Nigella sativa seeds seem to produce a therapeutic effect in lead induced cerebral toxicity, although the effects are not extremely significant.

\section{Contribution of Authors}

Z M Bauchi: Experimental design, concept, histological analysis, photomicroscopy and manuscript preparation.

D Kizito: practical experimentation, neurobehavioral studies and manuscript preparation.

A W Alhassan: Neurobehavioral studies.

S P Akpulu: Histology

J Timbuak: Statistical analysis and manuscript

\section{Conflicts of interest}

The authors declare that there is no conflict of interests in the publication of this paper.

\section{Acknowledgements}

The authors thank the Ahmadu Bello University, Zaria, Kaduna State, Nigeria for supporting this project. The authors would also like to thank the staff of the Histology Unit and neurobehavioral laboratory of the Human Anatomy Department, Faculty of Medicine, Ahmadu Bello University, Zaria, Kaduna State, Nigeria. 


\section{REFERENCES}

Adikwu,E., Oputiri D., Oru-Bo P. G and Enimeya D. A. (2013). Lead Organ and Tissue Toxicity: Roles of Mitigating Agents (Part 1). British Journal of Pharmacology and Toxicology 4(6): 232-240, 2013 ISSN: 2044-2459; eISSN: 2044-2467

Ahamed M and Siddiqui MK. (2007). Low level lead exposure and oxidative stress: current opinions. Clin Chim Acta 383(1-2): p. 57-64.

Al-Naggar, TB., G'omez-Serranillos, MP., Carretero, ME. and Villar, AM. (2003) Neuropharmacological activity of Nigella sativa L. extracts," Journal of Ethnopharmacology, 88 (1): 63- 68.

Azzubaidi, M. S., Saxena, A. K., Talib, N. A., Ahmed, Q. U. and Dogarai, B. B. S. (2012). Protective effect of treatment with black cumin oil on spatial cognitive functions of rats that suffered global cerebrovascular hypoperfusion. Acta Neurobiologiae Experimentalis, 72 (2): 154-165.

Borgesius NZ, de Waard MC, van der Pluijm I, Omrani A, Zondag GC, and van der Horst GT (2011). Accelerated age-related cognitive decline and neurodegeneration, caused by deficient DNA repair.J Neurosci; 31: 1254353.

Carobrez AP, Bertoglio LJ.( 2005) Ethological and temporal analyses of anxiety-like behavior: the elevated plus-maze model 20 years on. Neuroscience and Biobehavior Review.; 29:1193-1205.

Cory-Slechta DA. (1996). Legacy of lead exposure: consequences for the central nervous system. Otolaryngol Head Neck Surg 114: 224-226.

Elombah.com and HRW. (2012). Nigeria's Child Lead Poisoning Crisis is 'worst in modern history'.

El-Neweshy, M. and El-Sayed, Y. (2011). Influence of vitamin $C$ supplementation on lead-induced histopathological alterations in male rats. Exp. Toxicol. Pathol., 63(3): 221-227.

Fewtrell L, Kaufmann R, and Prüss-Üstün A (2003).Lead: Assessing the environmental burden of disease at national and local levels. Geneva, World Health Organization Environmental Burden of Disease Series, No.2;

http://www.who.int/quantifying ehimpacts/p ublications/en/leadebd2.pdf.

Hellion-Ibarrola MC, Ibarrola DA, Montabetti $Y$, Kennedy ML, Heinchem O,and Campuzano M. (2006)The anxiolytic like effects of Aloysia polystachya (Griseb) Moldenke (verbenaceae) in mice. J. Ethnopharmacol.; 105:400-8.

Hosseini, M., Mohammadpour, T., Karami, R., Rajaei, Z., Sadeghnia, H. R. and Soukhtanloo, M. (2015). Effects of the hydroalcoholic extract of Nigella Sativa on scopolamine-induced spatial memory impairment in rats and its possible mechanism. Chinese Journal of Integrative Medicine, vol. 21, no. 6, pp. 438444.

Kanter, M.(2008). Protective effects of Nigella sativa on the neuronal injury in frontal cortex and brain stem after chronic toluene exposure. Neurochemical Research, 33 (11):. 22412249.

Kanter, M. (2011) "Protective effects of thymoquinone on the neuronal injury in frontal cortex after chronic toluene exposure," Journal of Molecular Histology, 42 (1): 39-46

Khare CP. (2004) Encyclopedia of Indian Medicinal Plants. NewYork: Springes-Verlag Heidelberg.

Poli A, Salerno A, Laezza G, Dumontet S and Nicolaus B. (2009). Heavy metal resistance of some thermophiles: potential use of a- amylase from Anoxybacillis amylilyticus as a microbial enzymatic bioassay. Res. Microbial., 160(2):99-106

Sharma PC, Yelne MB, and Dennis TJ.(2005). Database on medicinal plants used in Ayurveda. New Delhi. p. 420-440.

Shepherd, J.K., Grewal, S.S., Fletcher, A., Bill, D.J. and Dourish, C.T. (1994).Current Topics in Behavioral

Neuroscience. Psychopharmacology, 116: 5664.

Thakur VD and. Mengi SA. (2005)Neuropharmacological profile of Eclipta albaL. Hassk. J. Ethnopharmacol.;102:23-31.

Walf AA and Frye CA. (2007). The use of elevated plus maze as an assay of anxiety related behavior in rodents. Nat Protoc 2(2) 322-328

WHO (2009). Global health risks: Mortality and burden of disease attributable to selected major risks. Geneva, World Health Organization (http://www.who.int/healthinfo/global burde n disease/GlobalHealthRisks report full.pdf.

Xu, J., Yan, H.C., Yang, B., Tong L.S. and Zou, Y.X. (2009). Effects of lead exposure on hippocampal metabotropic glutamate receptor subtype 3 and 7 in developmental rats. J. Negative Results BioMed., 8(5): 1-8. 